\title{
Clinicopathologic features and prognostic value of epidermal growth factor receptor mutation in patients with pT1a and pT1b invasive lung adenocarcinoma after surgical resection
}

\author{
Shiqi Chen ${ }^{1,2 \#}$, Siqian Yang ${ }^{3 \#}$, Yang Zhang ${ }^{1,2}$, Jiaqing Xiang ${ }^{1,2}$, Yawei Zhang ${ }^{1,2}$, Hong Hu ${ }^{1,2}$, Yihua Sun ${ }^{1,2}$, \\ Fangqiu Fu ${ }^{1,2}$, Chaoqiang Deng ${ }^{1,2}$, Shengping Wang ${ }^{2,4}$, Qiao Li ${ }^{2,4}$, Yajia Gu ${ }^{2,4}$, Yuan Li ${ }^{2,5}$, Xuxia Shen ${ }^{2,5}$, \\ Ting $\mathrm{Ye}^{1,2}$ \\ ${ }^{1}$ Department of Thoracic Surgery, Fudan University Shanghai Cancer Center, Shanghai, China; ${ }^{2}$ Department of Oncology, Shanghai Medical \\ College, Fudan University, Shanghai, China; ${ }^{3}$ School of Life Sciences, Fudan University, Shanghai, China; ${ }^{4}$ Department of Radiology, Fudan \\ University Shanghai Cancer Center, Shanghai, China; ${ }^{5}$ Department of Pathology, Fudan University Shanghai Cancer Center, Shanghai, China \\ Contributions: (I) Conception and design: S Chen, S Yang, T Ye; (II) Administrative support: T Ye; (III) Provision of study materials or patients: Y \\ Zhang, J Xiang, Y Zhang, H Hu, Y Sun, F Fu, C Deng, S Wang, Q Li, Y Gu, Y Li, X Shen; (IV) Collection and assembly of data: S Chen, S Yang, T \\ Ye; (V) Data analysis and interpretation: S Chen, S Yang, T Ye; (VI) Manuscript writing: All authors; (VII) Final approval of manuscript: All authors. \\ \#These authors contributed equally to this work. \\ Correspondence to: Ting Ye. Department of Thoracic Surgery, Fudan University Shanghai Cancer Center, 270 Dong'an Road, Xuhui District, \\ Shanghai 200032, China. Email: yeting831011@hotmail.com.
}

Background: Previous studies have evaluated the prognostic value of epidermal growth factor receptor (EGFR) mutation in different subgroups of lung adenocarcinoma, but there remains controversial on this issue. We conduct this study aimed to reveal the prognostic value of EGFR mutation in patients with pT1a and pT1b invasive lung adenocarcinoma.

Methods: From August 2009 to February 2015, 338 patients with pT1a and pT1b invasive lung adenocarcinoma who underwent EGFR mutation analysis were enrolled into this study. According to clinicopathologic and radiologic characteristics, survival analysis was conducted in different subgroups using Kaplan-Meier methods and Cox regression models.

Results: EGFR mutation was detected in 216 (63.9\%) patients. In the entire cohort, EGFR mutation was significantly frequent in female $(\mathrm{P}=0.011)$, never smoking $(\mathrm{P}=0.014)$ patients, patients with part-solid nodules $(\mathrm{P}=0.005)$ and patients with lepidic pattern-predominant adenocarcinoma (LPA)/acinar pattern-predominant adenocarcinoma (APA)/papillary pattern-predominant adenocarcinoma (PPA) $(\mathrm{P}=0.005)$. No difference in recurrence-free survival (RFS) was seen between patients harboring EGFR mutation and patients without EGFR mutation in the entire cohort $(\mathrm{P}=0.664)$ and the subgroup cohorts. Patients with EGFR mutation had a longer overall survival (OS) compared with patients without EGFR mutation in the entire cohort $(\mathrm{P}=0.005)$ and the subgroups of $\mathrm{N} 0$ stage cohort $(\mathrm{P}=0.013), \mathrm{N} 1-2$ stage cohort $(\mathrm{P}=0.033), \mathrm{APA} / \mathrm{PPA} /$ invasive mucinous adenocarcinoma (IMA) cohort $(\mathrm{P}=0.011)$ and pT1b cohort $(\mathrm{P}=0.002)$. Tyrosine kinase inhibitors (TKIs) could significantly prolong the $\mathrm{OS}$ in patients with EGFR mutation after recurrence $(\mathrm{P}=0.04)$.

Conclusions: EGFR mutation was not a risk factor for recurrence of patients with pT1a and pT1b invasive lung adenocarcinoma.

Keywords: Small lung adenocarcinoma; epidermal growth factor receptor (EGFR); recurrence-free survival (RFS)

Submitted Jun 04, 2021. Accepted for publication Jul 30, 2021.

doi: $10.21037 /$ jtd-21-924

View this article at: https://dx.doi.org/10.21037/jtd-21-924

(c) Journal of Thoracic Disease. All rights reserved. 


\section{Introduction}

Epidermal growth factor receptor (EGFR) mutation, which can promote cell proliferation and migration, is one of the most common oncogene mutations in lung adenocarcinoma of East Asian population (1). With the development of sequencing technology and targeted therapy, mutations in the tyrosine kinase (TK) domain (exons 18-21) of the EGFR in lung adenocarcinoma have been proved to be more sensitive to tyrosine kinase inhibitors (TKIs), such as gefitinib and erlotinib (2-6). Therefore, TKIs have been recommended as the first-line treatment for advanced lung adenocarcinoma patients with EGFR mutations (7), and the overall survival (OS) of patients with EGFR mutations have been reported to be improved significantly compared to those patients without EGFR mutations in previous studies (6). Additionally, EGFR mutation status is a predictor for the outcome of TKIs therapy (2).

However, whether the EGFR mutation itself has an impact on the prognosis of lung adenocarcinoma patients remains controversial. Several previous studies demonstrated that the status of EGFR mutation could predict the prognosis in lung adenocarcinoma patients (5,8-13). In contrast, some studies revealed that EGFR mutation was not a risk factor for postoperative recurrence of lung adenocarcinoma (3,14-20). Besides, most previous studies either did not consider the pathologic stage and pathologic tumor size, or did not exclude the influence of its histologic subtype, radiologic characteristics and TKIs therapy (21-23). Moreover, the radiologic component, histologic subtype, pathologic stage and TKIs therapy, which may have been related to the EGFR mutation, would significantly influence the prognosis of lung cancer based on previous studies $(1,2,5)$.

Therefore, we retrospectively analyzed the recurrencefree survival (RFS) of the pT1a (pathologic T1a) and p T1b (pathologic T1b) invasive lung adenocarcinoma patients who underwent radical surgery with reference to the status of EGFR mutation along with other clinicopathologic variables aimed to exclude the influence of TKIs therapy and ascertain its impact in small lung adenocarcinoma and analyzed the prognostic factor for OS.

We present the following article in accordance with the STROBE reporting checklist (available at https://dx.doi. org/10.21037/jtd-21-924).

\section{Methods}

\section{Patients}

Between August 2009 and February 2015, we retrospectively collected lung adenocarcinoma patients who received radical surgery at the Department of Thoracic Surgery, Fudan University Shanghai Cancer Center (FUSCC). This study was approved by the Ethics Committee of Fudan University Shanghai Cancer Center (No. 090977-1) and was performed in the light of the approved guidelines. Written informed consent was waived since it was a retrospective study. The study was conducted in accordance with the Declaration of Helsinki (as revised in 2013). The clinicopathologic data of all patients were recorded in the inpatient system of our hospital. In the current study, patients will be admitted to our study if they met the following criteria: (I) all pathologic slides were histologically confirmed diagnosis of invasive lung adenocarcinoma with pathologic tumor size no more than $2 \mathrm{~cm}$ by two experienced pathologist according to the International Association for the Study of Lung Cancer (IASLC)/American Thoracic Society (ATS)/European Respiratory Society (ERS) classification criteria and were grouped into three grades, lepidic patternpredominant adenocarcinoma (LPA) as low grade, acinar pattern-predominant adenocarcinoma (APA)/papillary pattern-predominant adenocarcinoma (PPA)/invasive mucinous adenocarcinoma (IMA) as intermediate grade, and micropapillary pattern-predominant adenocarcinoma (MPA)/solid pattern-predominant adenocarcinoma (SPA) as high grade; (II) radiological appearance of all patients were independently reviewed by two radiologists according to the thin-section computed tomography (CT) scan and were divided into three categories: pure ground-glass opacity (GGO), part-solid nodules and solid nodules; (III) EGFR mutations analysis was used sanger sequencing; (IV) follow-up was regular and the data was recorded completely. Finally, 338 patients with pT1a and pT1b invasive lung adenocarcinoma lesions were committed to our study. Demographic and clinicopathologic data such as gender, age, smoking history, histologic subtype, visceral pleural invasion (VPI) and lymphovascular invasion (LVI) of all patients included in the study were obtained from the electronic medical record. TNM classification were assessed according to the UICC $8^{\text {th }}$ TNM classification. 


\section{Follow-up and statistical analysis}

Follow-up was routinely conducted every 4 months for the first 3 years after surgery, followed by every 6 months for the next 2 years, and at 12 -month intervals thereafter. For every follow-up, we routinely checked patients' clinical symptoms, and then perform some necessary clinical examinations, such as chest CT, ultrasound, magnetic resonance imaging (MRI). Recurrence was defined as local recurrence and distant recurrence. RFS was defined as the time between the date of surgery to the date of disease recurrence or the last followup. OS time was calculated from the date of surgery to the date of death or the last follow-up.

All statistical analysis was conducted by SPSS 25.0 and GraphPad Prism 8. RFS and OS was estimated by the Kaplan-Meier method. Correlations between two groups were compared with Pearson's chi-square test or Fisher exact test. The log-rank test was used to identify potential prognostic factors such as radiologic component, $\mathrm{N}$ stage, EGFR status. Multivariate Cox regression models were used to explore independent prognostic factors. Variables with a $\mathrm{P}$ value less than 0.05 in univariate analysis would be included the multivariate survival analysis. The significance level for all statistics was set at $\mathrm{P}<0.05$ with two tail.

\section{Results}

\section{Patient characteristics and associations of EGFR mutation status with clinicopathologic features}

In this study, 338 patients, who were diagnosed as pT1a $(49,14.5 \%)$ and pT1b $(289,85.5 \%)$ invasive lung adenocarcinoma from August 2009 to February 2015, were admitted to the analysis cohort. EGFR mutation was found in 216 (63.9\%) patients, of whom exon 19 deletions mutation and L858R mutation in exon 21 were the two most frequent mutation, accounted for $44.9 \%$ and $47.7 \%$ respectively. Other types of EGFR mutations including exon 18, exon 20 were detected in $16(7.4 \%)$ patients. There were $186(55.0 \%)$ females and $152(45.0 \%)$ males, among whom $100(29.6 \%)$ were ever smokers and 238 (70.4\%) were never smokers, with the median age of 61 years (range, 24-82 years). According to radiologic component of tumor lesions, all patients were categorized as pure-GGO (13, $3.8 \%)$, part-solid nodules $(168,49.7 \%)$ and solid nodules $(157,46.4 \%)$ respectively. Among the histologic subtype, APA $(234,69.2 \%)$ was the most common subtype in our study, followed by LPA $(53,15.7 \%)$, PPA $(20,5.9 \%)$, SPA (16, 4.7\%), MPA $(8,2.4 \%)$ and IMA (7, 2.1\%). Lymph node metastasis could be found in $56(16.6 \%)$ patients. In the light of 8th Edition of the TNM Classification for Lung Cancer, all patients were divided into pathologic I A1 (47, 13.9\%), II A2 (235, 69.5\%), II B (15, 4.4\%) and III A (41, $12.1 \%$ ) respectively (Table 1).

This study found that female $(\mathrm{P}=0.011)$ and never smoking $(\mathrm{P}=0.014)$ patients were more susceptible to EGFR mutation. Moreover, EGFR mutation was more frequent in patients with part-solid nodules $(\mathrm{P}=0.005)$ and PPA/APA/ LPA $(\mathrm{P}=0.005$; Table 1).

\section{Prognostic value of EGFR mutation status}

During follow-up, 52 (15.4\%) patients died and 71 (21.0\%)

Table 1 Clinicopathologic characteristics of 338 patients with pT1a and pT1b invasive lung adenocarcinoma

\begin{tabular}{|c|c|c|c|c|c|c|c|}
\hline Variables & $\begin{array}{c}\text { Total } \\
(\mathrm{N}=338,100 \%)\end{array}$ & $\begin{array}{l}\text { Wild-type EGFR } \\
(\mathrm{N}=122,36.1 \%)\end{array}$ & $\begin{array}{c}\text { Mutated EGFR } \\
(\mathrm{N}=216,63.9 \%)\end{array}$ & $\begin{array}{c}\text { E19 del-mutation } \\
(\mathrm{N}=97,44.9 \%)\end{array}$ & $\begin{array}{l}\text { E21 L858R-mutation } \\
\quad(\mathrm{N}=103,47.7 \%)\end{array}$ & $\begin{array}{l}\text { Other mutations } \\
(\mathrm{N}=16,7.4 \%)\end{array}$ & $P$ value \\
\hline \multicolumn{8}{|c|}{ Age (years) } \\
\hline$<60$ & $143(42.3)$ & $44(30.8)$ & 99 (69.2) & $50(50.5)$ & $40(40.4)$ & $9(9.1)$ & 0.081 \\
\hline$\geq 60$ & $195(57.7)$ & $78(40.0)$ & $117(60.0)$ & 47 (40.2) & $63(53.8)$ & $7(6.0)$ & \\
\hline \multicolumn{8}{|l|}{ Gender } \\
\hline Female & $186(55.0)$ & $56(30.1)$ & $130(69.9)$ & 57 (43.8) & 64 (49.2) & $9(6.9)$ & \\
\hline \multicolumn{8}{|c|}{ Smoking history } \\
\hline Ever & $100(29.6)$ & $46(46.0)$ & $54(54.0)$ & $25(46.3)$ & $24(44.4)$ & $5(9.3)$ & 0.014 \\
\hline
\end{tabular}

Table 1 (continued) 
Table 1 (continued)

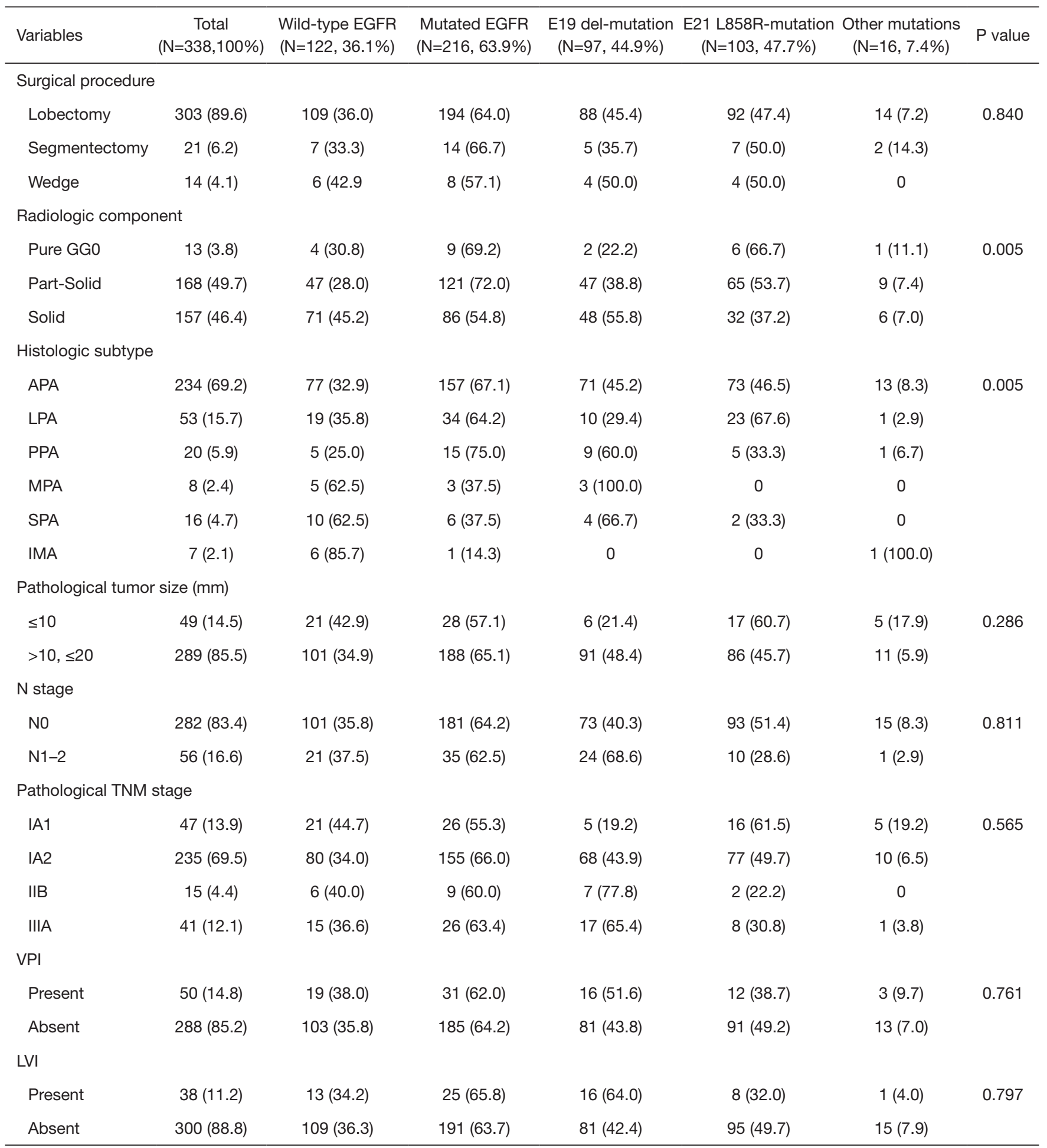

APA, acinar pattern-predominant adenocarcinoma; LPA, lepidic pattern-predominant adenocarcinoma; PPA, papillary pattern-predominant adenocarcinoma; MPA, micropapillary pattern-predominant adenocarcinoma; SPA, solid pattern-predominant adenocarcinoma; IMA, invasive mucinous adenocarcinoma; VPI, visceral pleural invasion; LVI, lymphovascular invasion. 
Table 2 Univariate and multivariate RFS and OS analysis of 282 patients in the entire cohort

\begin{tabular}{|c|c|c|c|c|c|c|c|c|}
\hline \multirow{3}{*}{ Variables } & \multicolumn{4}{|c|}{ RFS } & \multicolumn{4}{|c|}{ OS } \\
\hline & \multicolumn{2}{|c|}{ Univariate analysis } & \multicolumn{2}{|c|}{ Multivariate analysis } & \multicolumn{2}{|c|}{ Univariate analysis } & \multicolumn{2}{|c|}{ Multivariate analysis } \\
\hline & $\mathrm{HR}(95 \% \mathrm{Cl})$ & $P$ value & $\mathrm{HR}(95 \% \mathrm{Cl})$ & $P$ value & $\mathrm{HR}(95 \% \mathrm{Cl})$ & $\mathrm{P}$ value & $\mathrm{HR}(95 \% \mathrm{Cl})$ & $P$ value \\
\hline Age, years ( $\geq 60$ vs. $<60)$ & $1.195(0.750-1.905)$ & 0.455 & & & $3.266(1.894-5.631)$ & $<0.001$ & $\begin{array}{c}3.086 \\
(1.585-6.024)\end{array}$ & 0.001 \\
\hline $\begin{array}{l}\text { Radiologic component } \\
\text { (solid vs. part-solid) }\end{array}$ & 4.871 (3.057-7.759) & $<0.001$ & $\begin{array}{c}3.215 \\
(1.678-6.173)\end{array}$ & $<0.001$ & $5.986(3.474-10.31)$ & $<0.001$ & $\begin{array}{c}3.759 \\
(1.590-8.850)\end{array}$ & 0.003 \\
\hline $\begin{array}{l}\text { Surgical procedure (LOB } \\
\text { vs. SEG/WED) }\end{array}$ & $3.221(1.401-7.404)$ & 0.08 & & & $1.054(0.389-2.858)$ & 0.92 & & \\
\hline $\begin{array}{l}\text { Pathological tumor size } \\
\text { (T1b vs. T1a) }\end{array}$ & $1.314(0.676-2.553)$ & 0.463 & & & $1.502(0.682-3.304)$ & 0.382 & & \\
\hline N stage (N1-2 vs. N0) & $5.101(2.602-10.00)$ & $<0.001$ & $\begin{array}{c}3.215 \\
(1.934-5.319)\end{array}$ & $<0.001$ & $5.110(2.541-10.28)$ & $<0.001$ & $\begin{array}{c}3.257 \\
(1.799-5.882)\end{array}$ & $<0.001$ \\
\hline VPI (present vs. absent) & 1.887 (0.971-3.668) & 0.020 & & 0.495 & $2.047(0.985-4.256)$ & 0.015 & & 0.566 \\
\hline LVI (present vs. absent) & 2.387 (1.103-5.168) & 0.002 & & 0.512 & $3.452(1.511-7.891)$ & $<0.001$ & & 0.401 \\
\hline $\begin{array}{l}\text { EGFR mutation (yes vs. } \\
\text { no) }\end{array}$ & $0.899(0.551-1.468)$ & 0.664 & & & $0.468(0.263-0.832)$ & 0.005 & & 0.121 \\
\hline
\end{tabular}

RFS, recurrence-free survival; OS, overall survival; LOB, lobectomy; SEG, segmentectomy; WED, wedge; VPI, visceral pleural invasion; LVI, lymphovascular invasion; EGFR, epidermal growth factor receptor.

patients experienced recurrence. The most common site of recurrence was the local recurrence of lung (32, $45.1 \%)$, followed by the distant recurrence of bone (14, $19.7 \%)$, lymph node $(10,14.1 \%)$, pleura $(10,14.1 \%)$, brain (3, 4.2\%), liver (1, 1.4\%), kidney (1, 1.4\%). Among patients with node-positive disease, $44(78.6 \%)$ patients received adjuvant chemotherapy, 5 (8.9\%) patients received concurrent adjuvant radiotherapy and chemotherapy, there remained $7(12.5 \%)$ patients did not receive any adjuvant therapy. The median follow-up time was 64 months (interquartile range, 59-73 months) in all patients. In the entire cohort, 56 patients with LPA and pure-GGO nodules had an excellent survival, so we ruled out these patients for the further survival analysis. All patients did not receive EGFR-TKIs therapy before recurrence and 282 patients were admitted to the RFS analysis finally. The 5 -year RFS rates were $69 \%$ for patients with wild-type EGFR and $72 \%$ for patients with mutated EGFR respectively $(\mathrm{P}=0.664$;
Table 2). After recurrence, 27 of 45 patients with EGFR mutation received TKIs therapy. Eighteen of 45 patients with EGFR mutation did not receive TKIs therapy, of whom 9 patients received chemotherapy, 3 patients received radiotherapy and 6 patients did not receive chemotherapy or radiotherapy.

In the entire cohort, EGFR mutation status had no prognostic value for RFS ( $\mathrm{P}=0.664$; Table 2, Figure 1). In addition, univariate analysis revealed that EGFR mutation status was significantly associated with the OS of patients with pT1a and pT1b invasive lung adenocarcinoma after excluding LPA and pure GGO ( $\mathrm{P}=0.005$; Table 2, Figure 2). However, EGFR mutation status was not an independent prognostic factor for $\mathrm{OS}$ in the entire cohort $(\mathrm{P}=0.121$; Table 2).

We further evaluated the prognostic value of EGFR mutation status in the subgroups classified by $\mathrm{N}$ stage, pT stage, radiologic component and histologic subtype. 


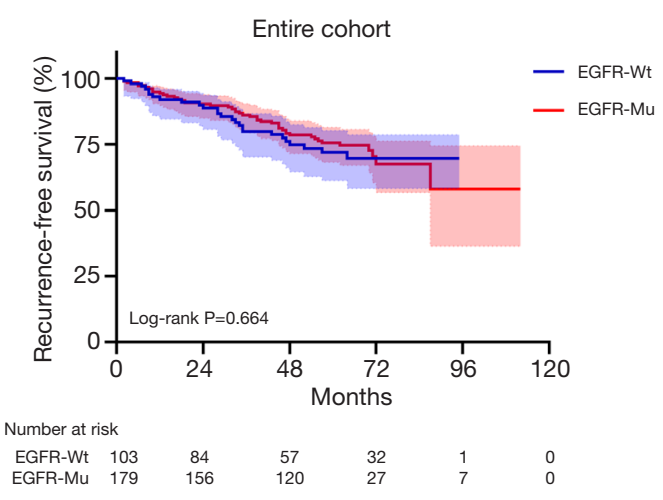

Figure 1 EGFR mutation status could not predict the recurrencefree survival in patients with pT1a and pT1b invasive lung adenocarcinoma after excluding LPA and puro GGO. EGFR, epidermal growth factor receptor; LPA, lepidic patternpredominant adenocarcinoma; GGO, pure ground-glass opacity.

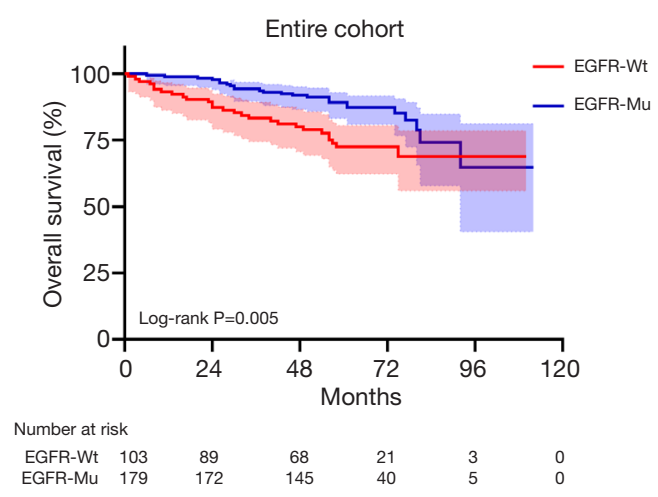

Figure 2 Univariate analysis revealed that EGFR mutation status was significantly associated with the overall survival of patients with pT1a and pT1b invasive lung adenocarcinoma after excluding LPA and puro GGO. EGFR, epidermal growth factor receptor; LPA, lepidic pattern-predominant adenocarcinoma; GGO, pure ground-glass opacity.

EGFR mutation status could still not predict the RFS time in the subgroup of $\mathrm{N} 0$ stage cohort $(\mathrm{P}=0.316$; Figure $3 A)$, N1-2 stage cohort $(\mathrm{P}=0.641$; Figure $3 B)$, part-solid cohort $(\mathrm{P}=0.388$; Figure $3 C)$, solid cohort $(\mathrm{P}=0.839$; Figure $3 D)$, APA/PPA/IMA cohort $(\mathrm{P}=0.857$; Figure $3 E)$ and $\mathrm{pT} 1 \mathrm{~b}$ cohort $(\mathrm{P}=0.218$; Figure $3 F)$. With regard to OS, EGFR mutation status had the prognostic value for OS in the subgroup of $\mathrm{N} 0$ stage cohort $(\mathrm{P}=0.013$; Figure $4 A)$, N1-2 stage $(\mathrm{P}=0.033$; Figure $4 B)$ cohort, APA/PPA/IMA cohort $(\mathrm{P}=0.011$; Figure $4 C)$ and $\mathrm{pT} 1 \mathrm{~b}$ cohort $(\mathrm{P}=0.002$; Figure $4 D)$ in univariate analysis, whereas part-solid cohort
$(\mathrm{P}=0.679$; Figure $4 E)$ and solid cohort $(\mathrm{P}=0.057$; Figure $4 F)$ did not. EGFR mutations had no independent prognostic significance for $\mathrm{OS}$ in the subgroup of $\mathrm{N} 0$ stage cohort $(\mathrm{P}=0.263), \mathrm{APA} / \mathrm{PPA} / \mathrm{IMA}$ cohort $(\mathrm{P}=0.107)$ and $\mathrm{pT} 1 \mathrm{~b}$ cohort $(\mathrm{P}=0.056)$ in multivariate analysis (Tables $3-5)$. pT1a cohort $(\mathrm{N}=36)$ and MPA/SPA cohort $(\mathrm{N}=24)$ failed to conduct survival analysis due to the smaller number of patients. Similarly, there was no significant difference in RFS between patients with wild type EGFR and patients with the two major mutations (E19del and E21L858R) of EGFR (Figures S1,S2).

\section{Discussion}

With the widespread application of thin-CT in the disease screening and physical examination, the number of small lung nodules are increasingly detected (24), and lung adenocarcinoma is one of the most common histologic subtypes of lung cancer (25). In addition, more and more patients choose important oncogene especially EGFR for sequencing due to the affordability of gene sequencing and the development of targeted therapy in order to better understand the disease and instruct the future treatment. Our previous study has revealed that EGFR mutation was a poor prognostic factor in specific subgroup including radiologic solid, histologic APA/PPA/IMA, and pathologic stage II and III lung adenocarcinomas (13). But there remains controversial in the prognostic value of EGFR mutation. Therefore, we conduct this study aimed to investigate the prognostic value of EGFR mutation in patients with small $(\mathrm{pT} \leq 2 \mathrm{~cm})$ invasive lung adenocarcinoma.

EGFR mutation status has been reported to be closely correlated with several clinicopathologic factors in lung adenocarcinoma including gender, smoking history, tumor size, pathologic TNM stage, radiologic component and histologic subtype in multiple previous studies $(3,14,15,26,27)$. Several previous studies showed that the presence of EGFR mutation was significantly frequent in female and never smokers, which was consistent with our present study (13). Besides, Lin et al. (14), whose study also focused on the small lung adenocarcinoma, recognized that EGFR mutation rate was significantly higher in patients with pT1b. However, our study found that the rate of EGFR mutation was similar in pT1a and pT1b $(57.1 \%$ vs. $65.1 \%, \mathrm{P}=0.286$ ), it might be explained that our study excluded adenocarcinoma in situ (AIS) and microinvasive adenocarcinoma (MIA) patients, which trend to be have a 

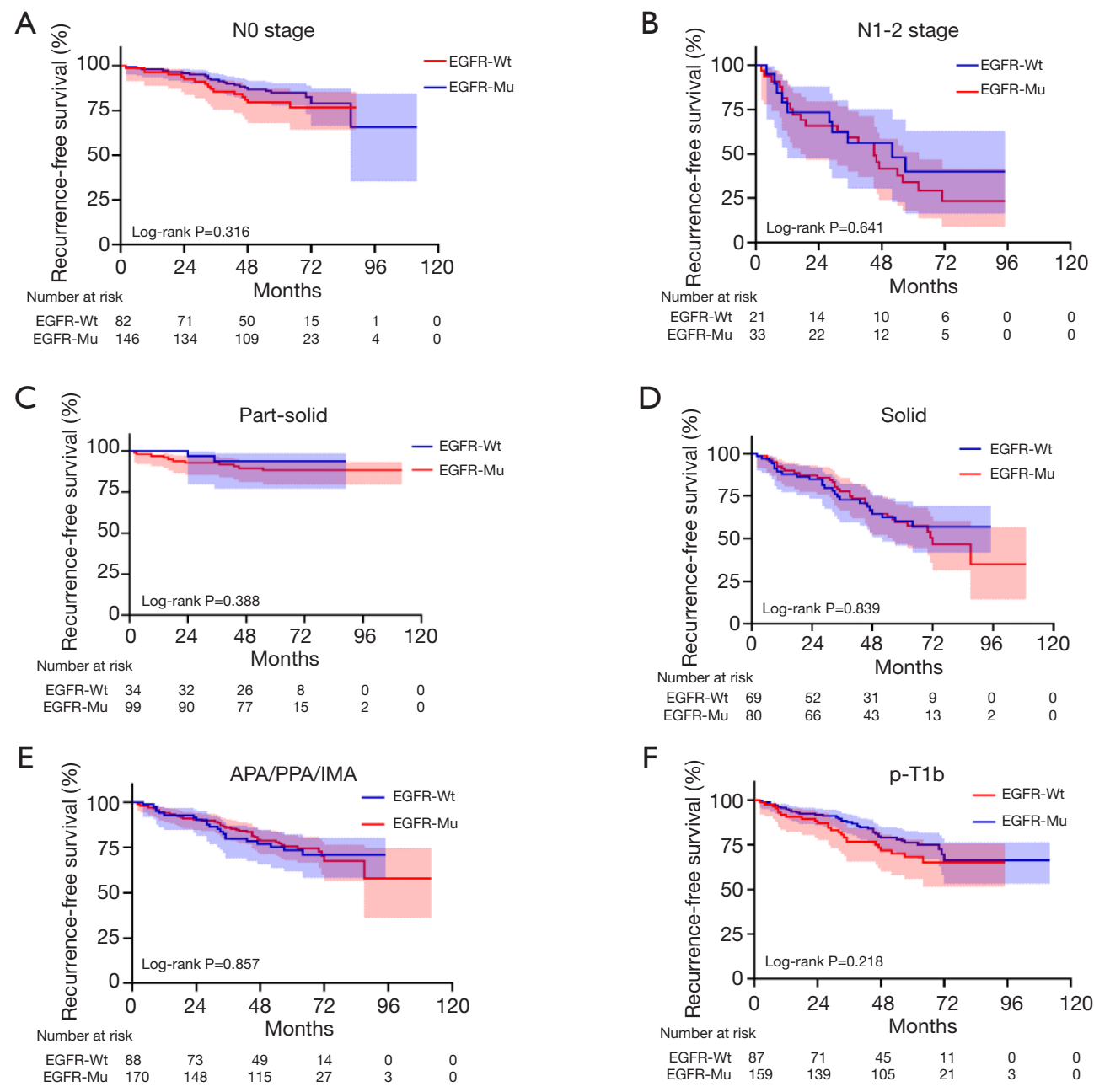

Figure 3 EGFR mutation status could not predict the recurrence-free survival in patients with different subgroups classified by $\mathrm{N}$ stage, radiologic component, histologic subtype and pathologic tumor size after excluding LPA and puro GGO. EGFR, epidermal growth factor receptor; LPA, lepidic pattern-predominant adenocarcinoma; GGO, pure ground-glass opacity.

smaller tumor size, whereas they did not. According to the radiologic component and histologic subtype, our study demonstrated that part-solid nodules and intermediategrade lung adenocarcinoma exist more mutated EGFR, which was in line with previous studies $(13,15,26,27)$.

EGFR mutation status has been reported to be a prognostic factor in several studies; some studies believed that EGFR mutation was a good prognostic factor for lung adenocarcinoma $(5,8,10,28)$, while others believed that it was a poor prognostic factor including our previous study $(12,13)$. To sum up, there remains controversial in the prognostic value of EGFR mutation. In our study, we choose RFS as a study endpoint in order to exclude the influence of TKIs therapy. In addition, we excluded patients with pure GGO and LPA in the survival analysis aimed to eliminate the bias caused by the excellent prognosis of patients with pure GGO and LPA. Our present study showed that EGFR mutation was not correlated with RFS in the entire cohort and the subgroups classified by clinicopathologic characteristics and radiologic component, which was similar to the research results of Matsumura et al. (17) and Lin et al. (14), whose studies also focused on the small lung adenocarcinoma and excluded the influence of TKI therapy. In addition, Ohba et al. (18) and colleagues found that EGFR mutation was not a prognostic factor in resected stage I lung adenocarcinoma. Moreover, our study revealed that RFS was also not significantly different between patients with wild type EGFR, E19del mutation 

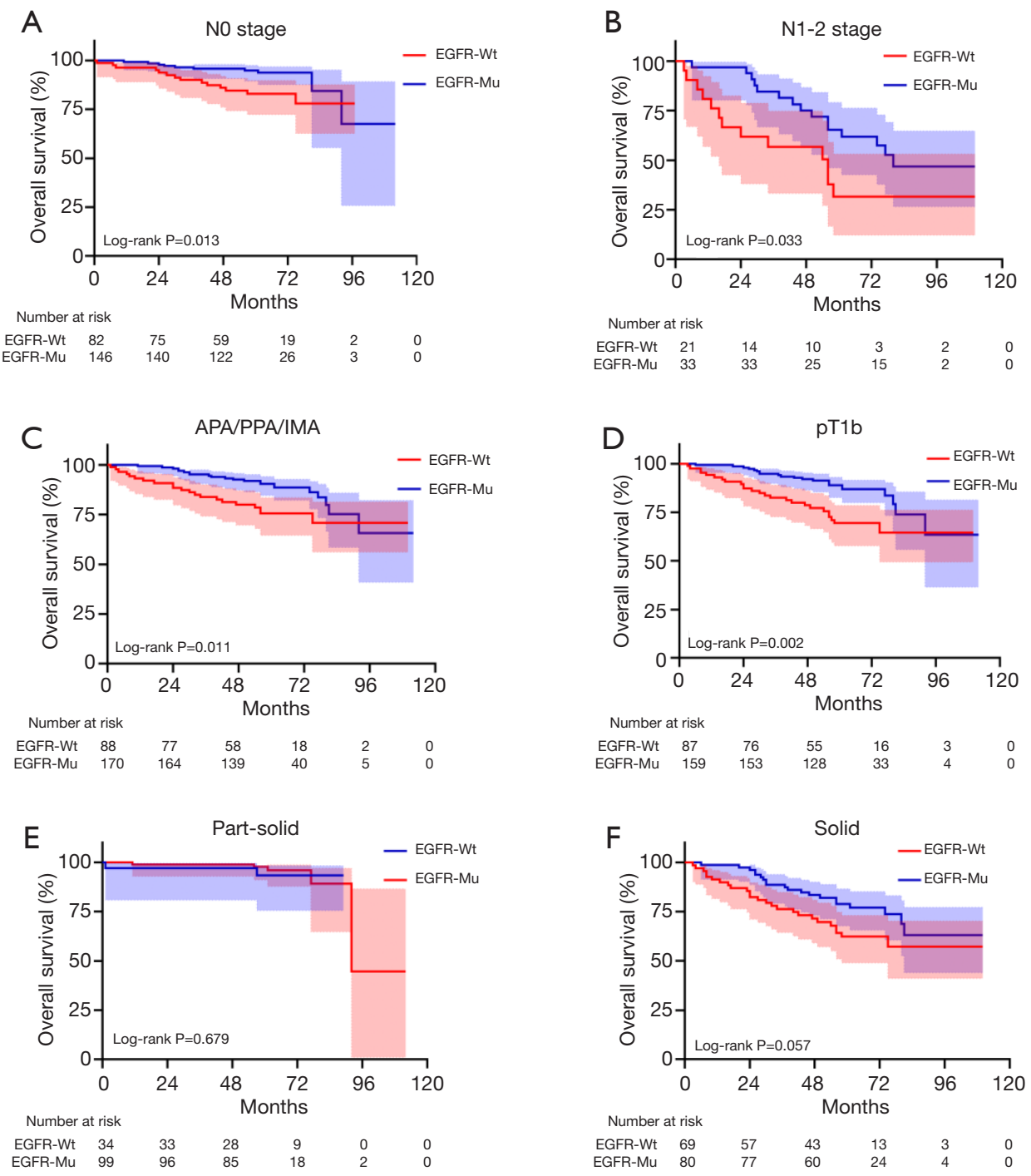

Figure 4 The prognostic value of EGFR mutation status in the subgroups of patients with pT1a and pT1b invasive lung adenocarcinoma after excluding LPA and puro GGO. EGFR, epidermal growth factor receptor; LPA, lepidic pattern-predominant adenocarcinoma; GGO, pure ground-glass opacity.

and E21L858R mutation. The similar results were found in the studies of Takamochi et al. (10) and Kosaka et al. (9), but they found that patients with EGFR mutations survived for a longer period than those without mutations. Angelo demonstrated that patients with EGFR mutation had a lower risk of death compared with patients without EGFR mutation, which might be accounted by the treatment of EGFR-TKIs. In our study, relapses were found in 45 patients with EGFR mutation, and the 5-year OS rate was higher in patients treated with TKIs than in those not treated with TKIs, which reveals that EGFR mutation is a predictor for EGFR TKIs response. Overall, our results suggested that EGFR mutation itself had no value in predicting the relapse in patients with $\mathrm{pT} 1 \mathrm{a}$ and $\mathrm{p} \mathrm{T} 1 \mathrm{~b}$ invasive lung adenocarcinoma, but it could predict the response of TKIs in patients with EGFR mutation after recurrence.

To the best of our knowledge, this is the largest study to compare the clinicopathologic characteristics and survival in relation to the status of EGFR mutation in patients with pT1a and pT1b invasive lung adenocarcinoma. However, there are some limitations. Firstly, although our study had 

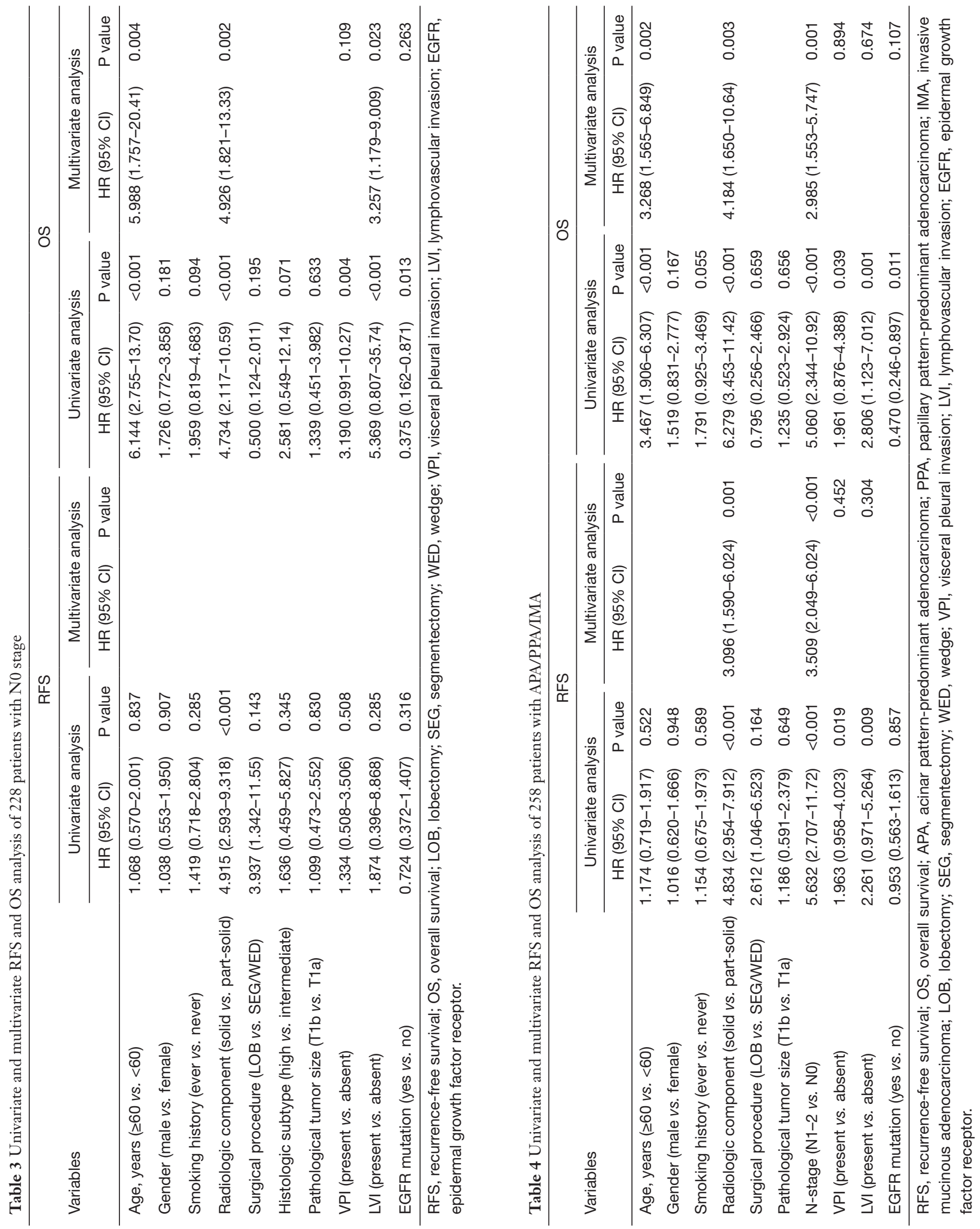


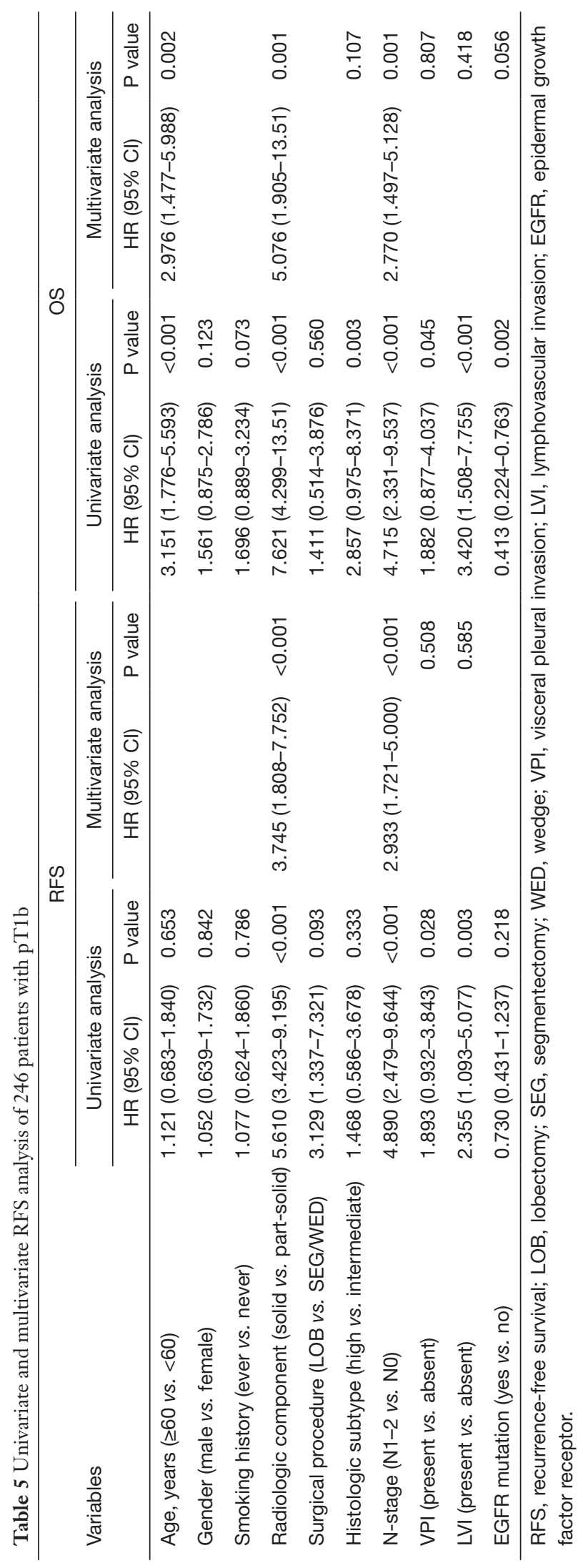

a larger population than the study of LIN, whose study also focused on the small lung adenocarcinoma, the bias of patients' selection and follow-up procedure were inevitable. Additionally, the occurrence and development of lung cancer is a complex process of multi-gene mutations, such as mutations in the driver gene EGFR and mutations in tumor suppressor gene TP53. Therefore, a single gene mutation may not be sufficient to explain the prognosis, further analysis of other genes mutation is needed.

\section{Conclusions}

EGFR mutation was not a risk factor for recurrence of patients with $\mathrm{pT} 1 \mathrm{a}$ and $\mathrm{pT} 1 \mathrm{~b}$ invasive lung adenocarcinoma.

\section{Acknowledgments}

Funding: This work was supported by the National Natural Science Foundation of China (81930073), Shanghai Science and Technology Innovation Action Project (20JC1417200), Shanghai Municipal Science and Technology Major Project (2017SHZDZX01, VBH1323001/026), Shanghai Municipal Key Clinical Specialty Project (SHSLCZDZK02104), and Pilot Project of Fudan University (IDF159045).

\section{Footnote}

Reporting Checklist: The authors have completed the STROBE reporting checklist. Available at https://dx.doi. org/10.21037/jtd-21-924

Data Sharing Statement: Available at https://dx.doi. org/10.21037/jtd-21-924

Peer Review File: Available at https://dx.doi.org/10.21037/ jtd-21-924

Conflicts of Interest: All authors have completed the ICMJE uniform disclosure form (available at https://dx.doi. org/10.21037/jtd-21-924). The authors have no conflicts of interest to declare.

Ethical Statement: The authors are accountable for all aspects of the work in ensuring that questions related to the accuracy or integrity of any part of the work are appropriately investigated and resolved. This study was approved by the Ethics Committee of Fudan University Shanghai Cancer Center (No. 090977-1) and was performed 
in the light of the approved guidelines. Written informed consent was waived since it was a retrospective study.

Open Access Statement: This is an Open Access article distributed in accordance with the Creative Commons Attribution-NonCommercial-NoDerivs 4.0 International License (CC BY-NC-ND 4.0), which permits the noncommercial replication and distribution of the article with the strict proviso that no changes or edits are made and the original work is properly cited (including links to both the formal publication through the relevant DOI and the license). See: https://creativecommons.org/licenses/by-nc-nd/4.0/.

\section{References}

1. Mitsudomi T, Kosaka T, Yatabe Y. Biological and clinical implications of EGFR mutations in lung cancer. Int J Clin Oncol 2006;11:190-8.

2. Lynch TJ, Bell DW, Sordella R, et al. Activating mutations in the epidermal growth factor receptor underlying responsiveness of non-small-cell lung cancer to gefitinib. N Engl J Med 2004;350:2129-39.

3. Shigematsu H, Lin L, Takahashi T, et al. Clinical and biological features associated with epidermal growth factor receptor gene mutations in lung cancers. J Natl Cancer Inst 2005;97:339-46.

4. Takano T, Ohe Y, Sakamoto H, et al. Epidermal growth factor receptor gene mutations and increased copy numbers predict gefitinib sensitivity in patients with recurrent non-small-cell lung cancer. J Clin Oncol 2005;23:6829-37.

5. D'Angelo SP, Janjigian YY, Ahye N, et al. Distinct clinical course of EGFR-mutant resected lung cancers: results of testing of 1118 surgical specimens and effects of adjuvant gefitinib and erlotinib. J Thorac Oncol 2012;7:1815-22.

6. Mitsudomi T, Kosaka T, Endoh H, et al. Mutations of the epidermal growth factor receptor gene predict prolonged survival after gefitinib treatment in patients with nonsmall-cell lung cancer with postoperative recurrence. J Clin Oncol 2005;23:2513-20.

7. Ettinger DS, Aisner DL, Wood DE, et al. NCCN Guidelines Insights: Non-Small Cell Lung Cancer, Version 5.2018. J Natl Compr Canc Netw 2018;16:807-21.

8. Izar B, Sequist L, Lee M, et al. The impact of EGFR mutation status on outcomes in patients with resected stage I non-small cell lung cancers. Ann Thorac Surg 2013;96:962-8.
9. Kosaka T, Yatabe Y, Onozato R, et al. Prognostic implication of EGFR, KRAS, and TP53 gene mutations in a large cohort of Japanese patients with surgically treated lung adenocarcinoma. J Thorac Oncol 2009;4:22-9.

10. Takamochi K, Oh S, Matsunaga T, et al. Prognostic impacts of EGFR mutation status and subtype in patients with surgically resected lung adenocarcinoma. J Thorac Cardiovasc Surg 2017;154:1768-1774.e1.

11. Ito M, Miyata $Y$, Tsutani $Y$, et al. Positive EGFR mutation status is a risk of recurrence in pN0-1 lung adenocarcinoma when combined with pathological stage and histological subtype: A retrospective multi-center analysis. Lung Cancer 2020;141:107-13.

12. Ito $M$, Miyata $Y$, Kushitani $\mathrm{K}$, et al. Increased risk of recurrence in resected EGFR-positive pNOM0 invasive lung adenocarcinoma. Thorac Cancer 2018;9:1594-602.

13. Deng C, Zhang Y, Ma Z, et al. Prognostic value of epidermal growth factor receptor gene mutation in resected lung adenocarcinoma. J Thorac Cardiovasc Surg 2020. [Epub ahead of print]. doi: 10.1016/ j.jtcvs.2020.05.099.

14. Lin MW, Wu CT, Shih JY, et al. Clinicopathologic characteristics and prognostic significance of EGFR and $\mathrm{p} 53$ mutations in surgically resected lung adenocarcinomas $\leq 2 \mathrm{~cm}$ in maximal dimension. J Surg Oncol 2014;110:99-106.

15. Kaseda K, Asakura K, Kazama A, et al. Clinicopathological and prognostic features of surgically resected pathological stage I lung adenocarcinoma harboring epidermal growth factor receptor and K-ras mutation. Thorac Cancer 2017;8:229-37.

16. Ragusa M, Vannucci J, Ludovini V, et al. Impact of epidermal growth factor receptor and KRAS mutations on clinical outcome in resected non-small cell lung cancer patients. Am J Clin Oncol 2014;37:343-9.

17. Matsumura Y, Suzuki H, Ohira T, et al. Matchedpair analysis of a multi-institutional cohort reveals that epidermal growth factor receptor mutation is not a risk factor for postoperative recurrence of lung adenocarcinoma. Lung Cancer 2017;114:23-30.

18. Ohba T, Toyokawa G, Kometani T, et al. Mutations of the EGFR and K-ras genes in resected stage I lung adenocarcinoma and their clinical significance. Surg Today 2014;44:478-86.

19. Liu WS, Zhao LJ, Pang QS, et al. Prognostic value of epidermal growth factor receptor mutations in resected lung adenocarcinomas. Med Oncol 2014;31:771.

20. Zhang Z, Wang T, Zhang J, et al. Prognostic value of 
epidermal growth factor receptor mutations in resected non-small cell lung cancer: a systematic review with metaanalysis. PLoS One 2014;9:e106053.

21. Fu F, Zhang Y, Wen Z, et al. Distinct Prognostic Factors in Patients with Stage I Non-Small Cell Lung Cancer with Radiologic Part-Solid or Solid Lesions. J Thorac Oncol 2019;14:2133-42.

22. Zhang Y, Wang R, Cai D, et al. A comprehensive investigation of molecular features and prognosis of lung adenocarcinoma with micropapillary component. J Thorac Oncol 2014;9:1772-8.

23. Yuan Y, Ma G, Zhang Y, et al. Presence of micropapillary and solid patterns are associated with nodal upstaging and unfavorable prognosis among patient with cT1N0M0 lung adenocarcinoma: a large-scale analysis. J Cancer Res Clin Oncol 2018;144:743-9.

24. Zhang Y, Jheon S, Li H, et al. Results of low-dose computed tomography as a regular health examination among Chinese hospital employees. J Thorac Cardiovasc Surg 2020;160:824-831.e4.

Cite this article as: Chen S, Yang S, Zhang Y, Xiang J, Zhang Y, Hu H, Sun Y, Fu F, Deng C, Wang S, Li Q, Gu Y, Li Y, Shen X, Ye T. Clinicopathologic features and prognostic value of epidermal growth factor receptor mutation in patients with pT1a and pT1b invasive lung adenocarcinoma after surgical resection. J Thorac Dis 2021;13(9):5496-5507. doi: 10.21037/jtd-21924
25. Yoshimi I, Ohshima A, Ajiki W, et al. A comparison of trends in the incidence rate of lung cancer by histological type in the Osaka Cancer Registry, Japan and in the Surveillance, Epidemiology and End Results Program, USA. Jpn J Clin Oncol 2003;33:98-104.

26. Sonobe M, Manabe T, Wada H, et al. Mutations in the epidermal growth factor receptor gene are linked to smoking-independent, lung adenocarcinoma. Br J Cancer 2005;93:355-63.

27. Kosaka T, Yatabe Y, Endoh H, et al. Mutations of the epidermal growth factor receptor gene in lung cancer: biological and clinical implications. Cancer Res 2004;64:8919-23.

28. Kudo Y, Shimada Y, Saji H, et al. Prognostic Factors for Survival After Recurrence in Patients With Completely Resected Lung Adenocarcinoma: Important Roles of Epidermal Growth Factor Receptor Mutation Status and the Current Staging System. Clin Lung Cancer 2015;16:e213-21. 


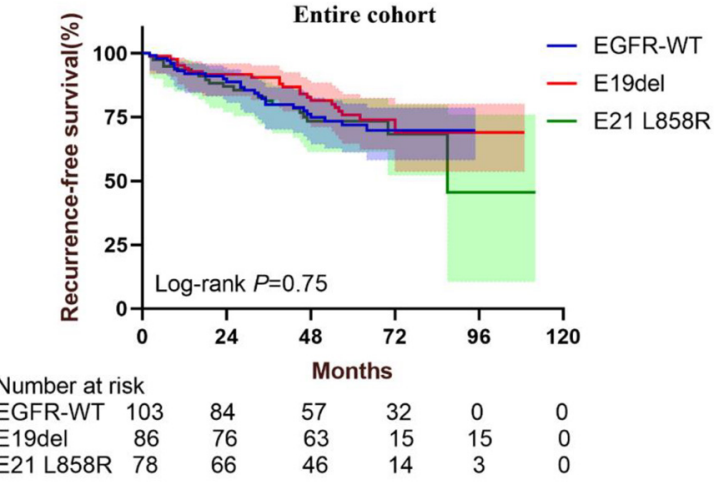

Figure S1 EGFR mutation types could not predict the recurrence-free survival in patients with pT1a and pT1b invasive lung adenocarcinoma after excluding LPA and puro GGO. EGFR, epidermal growth factor receptor; LPA, lepidic pattern-predominant adenocarcinoma; GGO, pure ground-glass opacity.
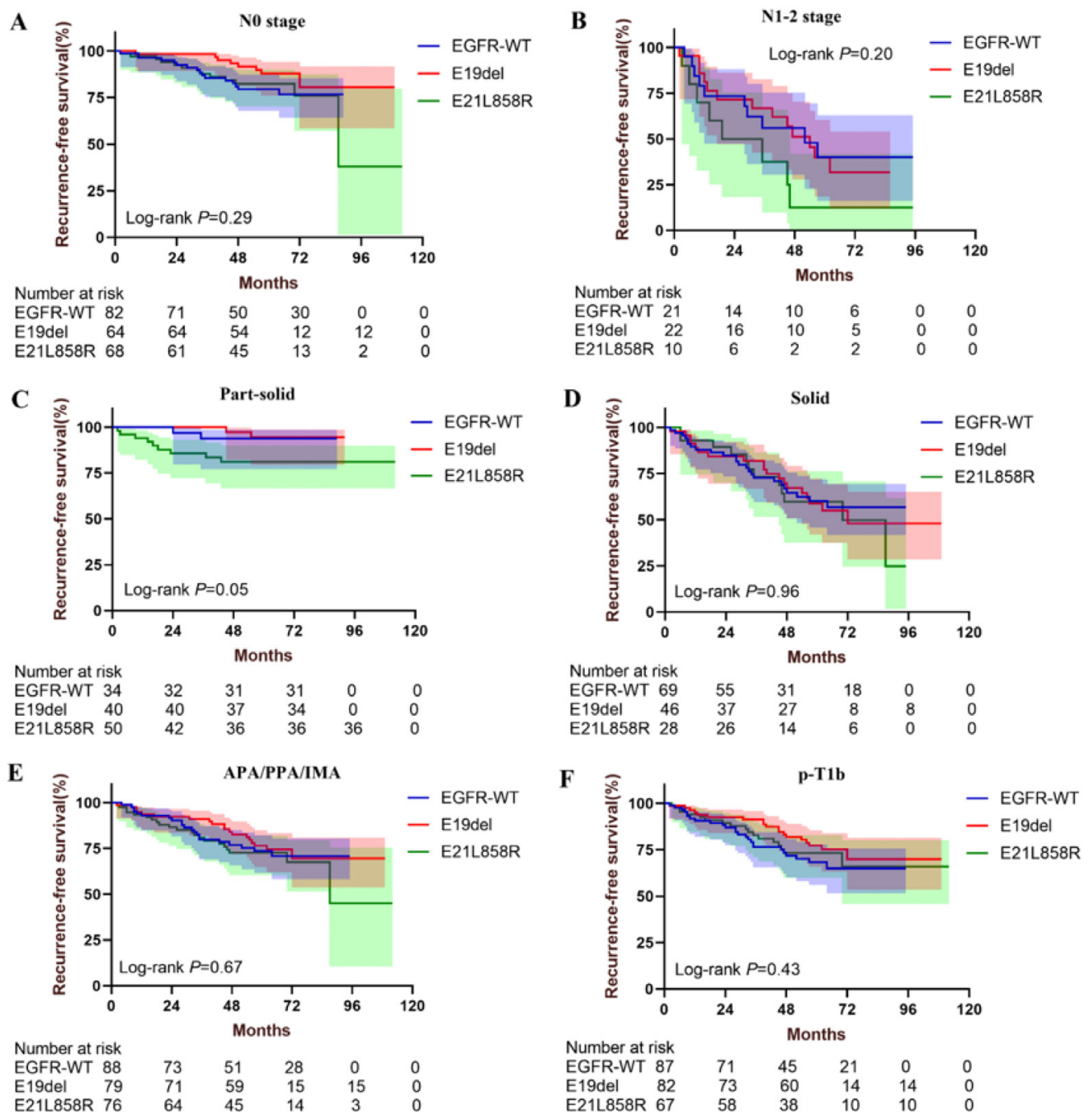

Figure S2 EGFR mutation types could not predict the recurrence-free survival in patients with different subgroups of pT1a and pT1b invasive lung adenocarcinoma after excluding LPA and puro GGO. EGFR, epidermal growth factor receptor; LPA, lepidic patternpredominant adenocarcinoma; GGO, pure ground-glass opacity. 